\title{
OONF $941144-65$
}

VACANCY RELATED DEFECTS IN THIN FILM Pb(ZrTi)O $\mathrm{O}_{3}$ MATERIALS

\author{
A. KRISHNAN ${ }^{*}$, D.J.KEEBLE* ${ }^{*}$, R. RAMESH ${ }^{\dagger}$, W.L. WARREN ${ }^{* *}$, B.A. TUTTLE ${ }^{* *}$, R.L.PFEF- \\ FER $^{+}$, B. NIELSEN ${ }^{\dagger \dagger}$ AND K.G. LYNN ${ }^{\dagger \dagger}$ \\ *Michigan Technological University, Department of Physics, Houghton, MI 49931 \\ ${ }^{\dagger}$ Bell Communications, Red Bank, NJ07768 \\ ${ }^{* *}$ Sandia National Laboratories, Albuquerque, NM 87185-1349 \\ ${ }^{+}$United States Army Research Laboratories, Fort Monmouth, NJ 07703 \\ ${ }^{\dagger \dagger}$ Brookhaven National Laboratory, Upton, NY 11973
}

\section{ABSTRACT}

Positron annihilation techniques have been applied to characterize vacancy-related defects in ferroelectric thin film structures. Variable energy positron beam measurements were carried out on doped and undoped $\mathrm{Pb}(\mathrm{Zr}, \mathrm{Ti}) \mathrm{O}_{3}$ (PZT) samples subjected to different post-deposition cool down and anneal conditions. The PZT was deposited by sol-gel with either with platinum or $\mathrm{RuO}_{2}$ electrodes, or by laser ablation with $\mathrm{La}_{0.5} \mathrm{Sr}_{0.5} \mathrm{CoO}_{3}$ electrodes. The $\mathrm{RuO}_{2}$ and $\mathrm{La}_{0.5} \mathrm{Sr}_{0.5} \mathrm{CoO}_{3}$ electrode samples showed a smaller S-parameter compared to those deposited with Pt electrodes consistent with an improved PZT layer quality. For laser ablated samples cooled in a reducing ambient an increase in $\mathrm{S}$-parameter for both the PZT and $\mathrm{La}_{0.5} \mathrm{Sr}_{0.5} \mathrm{CoO}_{3}$ layers was observed indicating an increase in neutral or negatively charged open-volume defects.

\section{INTRODUCTION}

It has been suggested that vacancy-related defects are involved in the mechanisms responsible for fatigue and for voltage offset behavior encountered in ferroelectric perovskite oxide based devices $^{1,2}$. Positron annihilation is sensitive to open-volume defects with neutral or negative charge and hence is expected to detect the presence of $\mathrm{Pb}$ vacancies, certain vacancy-impurity complexes, and vacancy clusters, e.g. $V_{P b}^{\prime \prime} V_{o}^{*}$. Defects may result from material processing. Impurities may act as acceptors or donors depending on whether they incorporated with a resultant charge less or more positive than the ion they replace ${ }^{3}$. Acceptors represent a local negative charge relative to the ideal lattice. This charge can be compensated by positively charged oxygen vacancies. Under oxidizing conditions, the oxygen vacancies can be partially filled from the gas phase to give oxygen-excess compositions that are p-type conductors. This is an undesirable property for dielectrics. Lead titanate zirconate contains two volatile components, lead and oxygen. At the normal sintering temperatures $\mathrm{PbO}$ can be lost leaving behind lead and oxygen vacancies ${ }^{4}$. These defects can also form bound complexes.
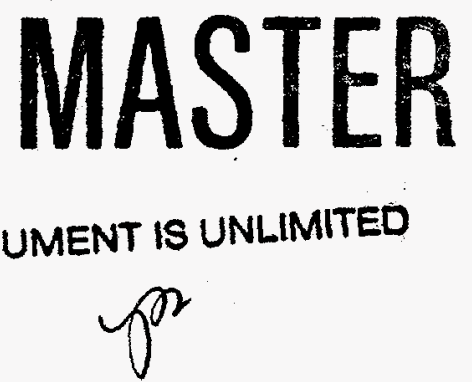
Donors represent a net positive charge, e.g. $\mathrm{La}^{3+}$ substituting for $\mathrm{Pb}^{2+}$ in $\mathrm{PZT}$ and $\mathrm{Nb}^{+5}$ substituting for $\mathrm{Ti}^{+4}$ in PNZT. The donor oxide contains more oxygen per cation than the host ion it replaces. The excess oxygen is accommodated either by creating new unit cells or by expelling the excess oxygen as neutral atoms, leaving behind electrons. In the case of ionic compensation of the charged donor centers, the materials are excellent insulators. This is because the concentration of positively charged oxygen vacancies is strongly suppressed by the large concentration of positively charged donor centers. Electron compensation can take place in any donor-doped reduction-type (compounds that contain reducible cations such as titanium and zirconium) perovskites processed in a highly reducing atmosphere ${ }^{5}$. Lanthanum enters into the material at the A-site. It has been shown ${ }^{6}$ that for lanthanum content $<5 \mathrm{~mol} \%$, vacancies may occur exclusively at lead sites, while for lanthanum content $>5 \mathrm{~mol} \%$, vacancies also may occur at titanium sites for charge compensation.

The positrons implanted in a solid slow down rapidly, attaining thermal energies in about 10 ps and then annihilate with the electrons ${ }^{7}$. Any contribution to the momentum of the annihilating pair comes from the annihilated electrons. Because of the finite momentum of the annihilating pair, the two gamma-rays are not exactly collinear in the laboratory frame. The longitudinal component of the pair momentum results in a Doppler shift in the energy of the photons measured in the laboratory frame. Thermalized positrons enter a $\mathrm{k} \approx 0$ Bloch state in undefected crystalline materials. However, the lack of a nucleus or the presence of a negative ion will cause localization. When a positron wave function localizes at a vacancy, overlap with the more energetic core electrons is reduced relative to the less tightly bound conduction electrons. This leads to a reduction in the Doppler broadening of the energy spectrum. The Doppler lineshape is characterized by a shape parameter; the S parameter, which is the fraction of counts in the central region, or the W parameter, which is the fraction of counts in the wings. The $S$ parameter measures the fraction of low momentum annihilations and so it is larger for a positron annihilating at a vacancy. The absolute value of the S-parameter is not relevant since it depends on the energy windows chosen in defining the S-parameter. In the variable energy positron beam experiment, positrons emitted from a radioactive source are moderated and then accelerated to fixed potentials thereby controlling the positron implantation energy. This energy is stepped allowing the positron annihilation parameters to be measured as a function of implantation depth.

\section{EXPERIMENTAL}

A series of sol-gel fabricated La-doped (4\%) $\mathrm{Pb}\left(\mathrm{Zr}_{0.3} \mathrm{Ti}_{0.7}\right) \mathrm{O}_{3}$ ( $\mathrm{PLZT} \mathrm{4/30/70)} \mathrm{capacitor}$ structures subjected to different post-growth annealing were studied. The samples had either $\mathrm{Pt}$ and with $\mathrm{RuO}_{2}$ electrodes. Niobium doped (4\%) $\mathrm{Pb}\left(\mathrm{Zr}_{0.3} \mathrm{Ti}_{0.7}\right) \mathrm{O}_{3}$ (PNZT) capacitors with $\mathrm{Pt}$ electrodes were also studied. Following deposition of the ferroelectric layer, samples were annealed at $650^{\circ} \mathrm{C}$ in air for 30 mins, a similar treatment was made after deposition of the top electrode. A schematic of these samples is shown in Figure 1, and a full description is given in Table 1. Samples fabricated by laser ablation were also studied, see Table 1. These were grown on single crystal $\mathrm{LaAlO}_{3}$ substrates. For the capacitor structures, near epitaxial $100 \mathrm{~nm}$ electrodes nominally $\mathrm{La}_{0.5} \mathrm{Sr}_{0.5} \mathrm{CoO}_{3}$ (LSCO) were used. The ferroelectric layer was $300 \mathrm{~nm}$ thick. Deposition was carried out at $650^{\circ} \mathrm{C}$ in a 100 mtorr oxygen ambient.

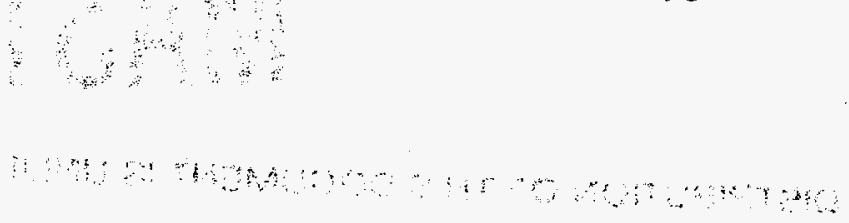




\section{DISCLAIMER}

Portions of this document may be illegible in electronic image products. Images are produced from the best available original document. 


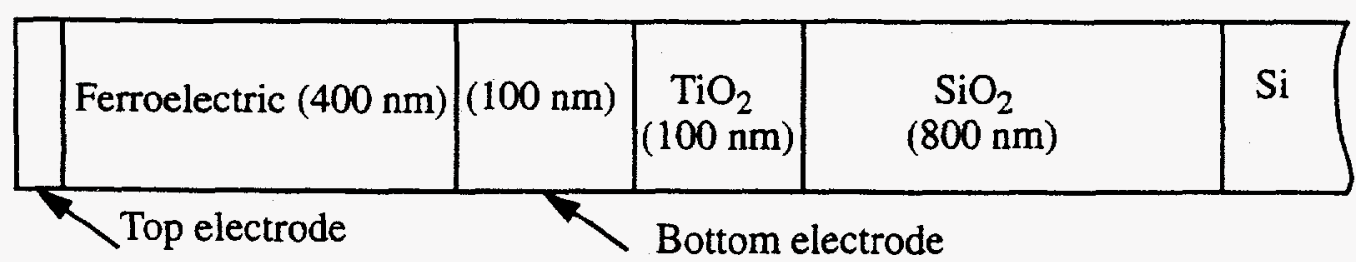

Figure 1-Sol-gel ferroelectric capacitor structure. The thickness of the top electrode was $20 \mathrm{~nm}$ for Pt and $50 \mathrm{~nm}$ for $\mathrm{RuO}_{2}$.

TABLE I Thin-film PZT Samples

\begin{tabular}{|l|l|l|l|}
\hline Sample & Electrode & Ferroelectric & Post-growth conditions \\
\hline Sol-Gel Thin Film Samples & PZT $0 / 30 / 70$ & as-grown \\
\hline PA1 & $\mathrm{Pt}$ & & $150^{\circ} \mathrm{C}$ vacuum anneal \\
\hline PA2 & $\mathrm{Pt}$ & & $600^{\circ} \mathrm{C}$ vacuum anneal \\
\hline PA3 & $\mathrm{Pt}$ & & $400^{\circ} \mathrm{C} \mathrm{N}_{2}$ anneal \\
\hline PA4 & $\mathrm{Pt}$ & PNZT & as-grown \\
\hline PA11 & $\mathrm{Pt}$ & PZT $0 / 30 / 70$ & as-grown \\
\hline PA6 & RuO & \\
\hline Laser Ablated Thin Film Samples & \multicolumn{1}{|l|}{} \\
\hline LP200 & LSCO & $10 / 20 / 80$ & cooled 750 torr $\mathrm{O}_{2}$ \\
\hline LP201 & LSCO & $10 / 20 / 80$ & cooled $10^{-5}$ torr $\mathrm{O}_{2}$ \\
\hline LP227 & none & $0 / 20 / 80$ & cooled 750 torr $\mathrm{O}_{2}$ \\
\hline
\end{tabular}

Variable energy positron beam measurements were carried out at Brookhaven National Laboratory. The S-parameter was defined as the ratio of counts in the region 510.25 to 511.75 to the total for the Doppler broadened annihilation $\gamma$-ray energy spectrum. Rutherford backscattering and oxygen sensitive $3.05 \mathrm{MeV}{ }^{4} \mathrm{He}$ backscattering measurements were performed on samples LP200 and LP201 at the Army Research Laboratory.

\section{RESULTS AND DISCUSSION}

The variable energy positron beam measurements on the sol-gel deposited structures are shown in Figures 2 and 3. A comparison of the as-grown layers for the PZT with Pt and with $\mathrm{RuO}_{2}$ and with the PNZT with Pt electrodes is shown in Figure 2. The positron implantation energy at a depth of $20 \mathrm{~nm}$ in $\mathrm{Pt}$ is approximately $4.5 \mathrm{keV}$ and is approximately $4.3 \mathrm{keV}$ for a

\section{DISCLAIMER}

This report was prepared as an account of work sponsored by an agency of the United States Government. Neither the United States Government nor any agency thereof, nor any of their employees, makes any warranty, express or implied, or assumes any legal liability or responsibility for the accuracy, completeness, or usefulness of any information, apparatus, product, or process disclosed, or represents that its use would not infringe privately owned rights. Reference herein to any specific commercial product, process, or service by trade name, trademark, manufacturer, or otherwise does not necessarily constitute or imply its endorsement, recommendation, or favoring by the United States Government or any agency thereof. The views and opinions of authors expressed herein do not necessarily state or reflect those of the United States Government or any agency thereof. 


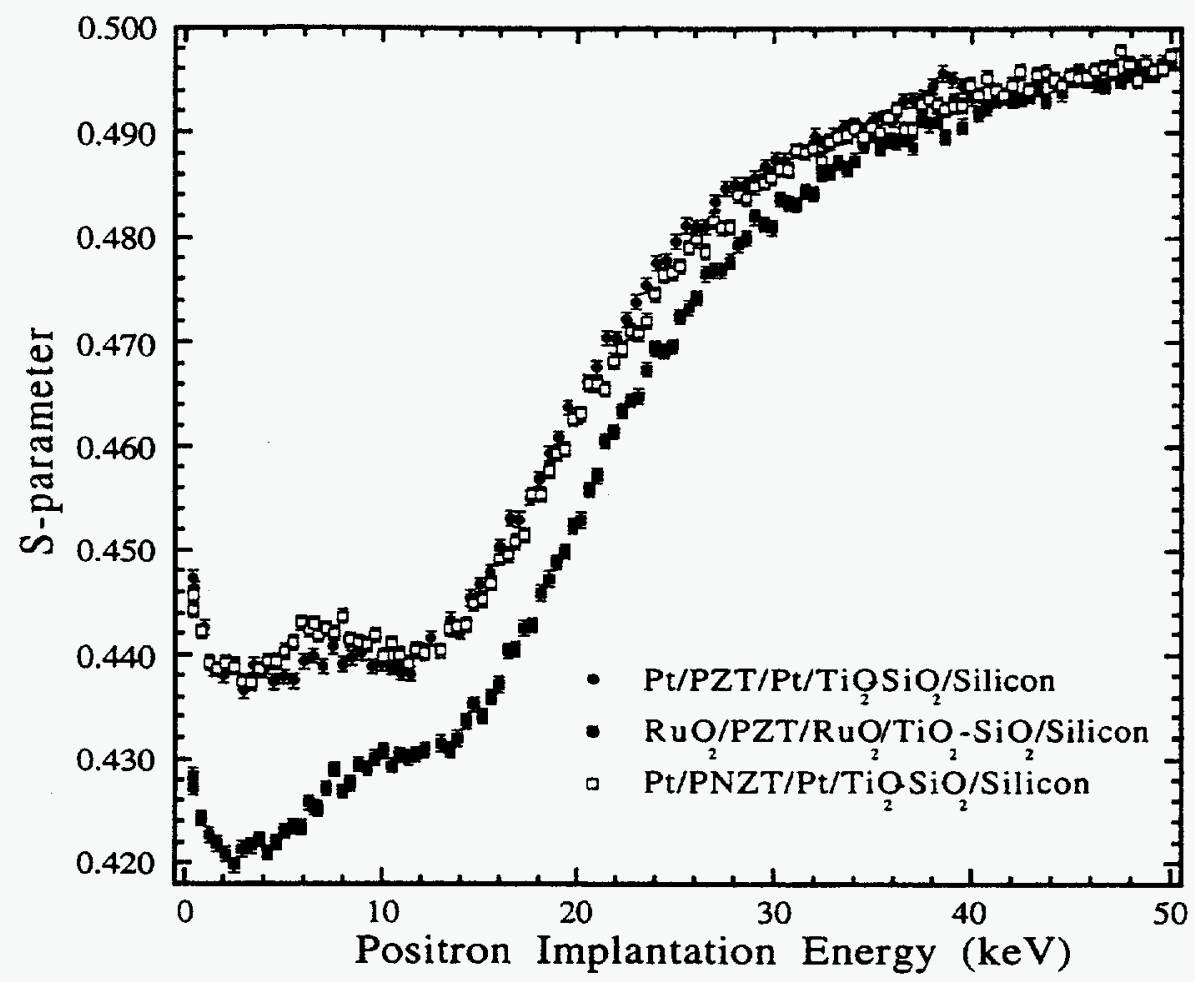

Figure 2- VEPB measurements on as-grown sol-gel capacitor structures

depth of $50 \mathrm{~nm}$ in $\mathrm{RuO}_{2}$. The ferroelectric layer for these structures spans approximately $10 \mathrm{keV}$ of positron implantation energy. The effects of annealing these layers is shown in Figure 3. It can be seen that annealing in vacuum at $600^{\circ} \mathrm{C}$ results in an increase in S-parameter while changes

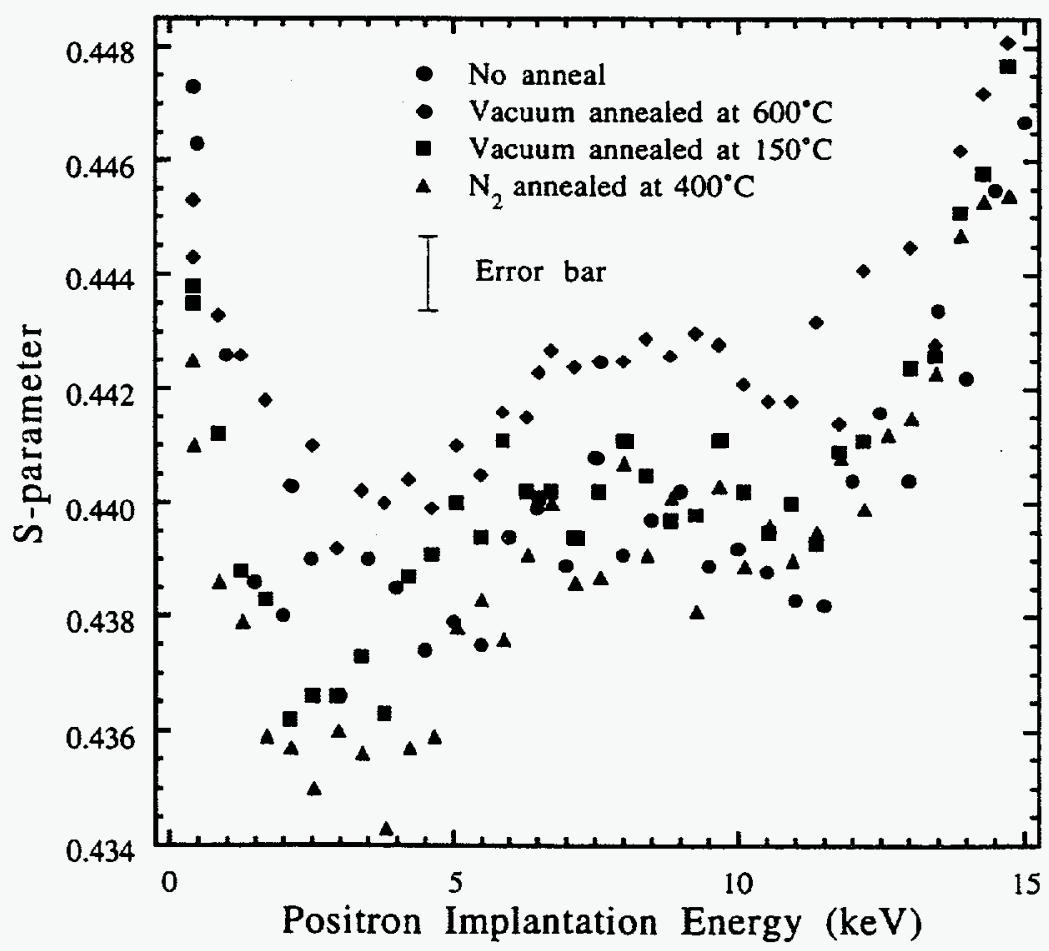

Figure 3- Sol-gel Pt/PZT/Pt capacitors subjected to different post-growth anneals. 


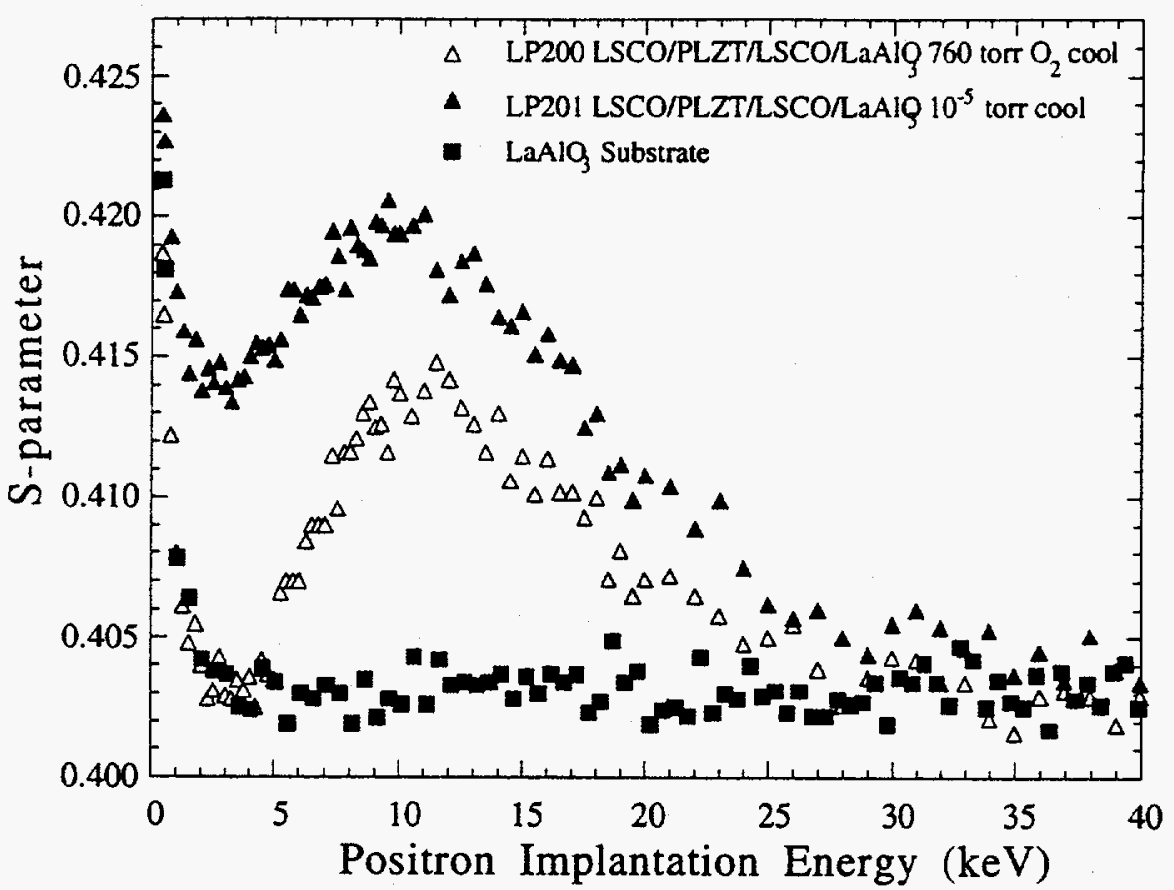

Figure 4- Laser ablated LSCO/PLZT/LSCO capacitors cooled in $1 \mathrm{~atm}$ oxygen and in a reducing enviroment.

induced by the other anneals are less marked. The VEPB results on laser ablated LSCO/PLZT/ LSCO/LaAlO 3 capacitors are shown in Figure 4. The S-parameter is larger for both the LSCO electrode as well as the PLZT layer for the sample cooled in $10^{-5}$ torr vacuum. The loss of oxygen in the sample cooled in vacuum was confirmed by resonant ${ }^{4} \mathrm{He}$ backscattering measurements LP200 and 201. Simulation of the S-parameter vs. implantation energy data is in progress.

\section{CONCLUDING REMARKS}

The VEPB measurements presented here indicate that post-crystallization processing in a reducing ambient results in an increase in neutral or negative vacancy-related defects. Positron annihilation is not expected to be sensitive to isolated oxygen vacancy defects. It is inferred that lead vacancies and or lead vacancy complexes are generated during processing in vacuum.

\section{ACKNOWLEDGMENTS}

Work performed by DJK and AK was funded by Sandia National Laboratories. The portion of the work performed at Sandia National Laboratories was supported by the U.S. Department of Energy under contract DE-AC04-94AL85000 and by the Advanced Research Projects Agency. Supported in part by the U.S.Dept. of Energy, Division of Materials Science, under Contract No. DE-AC02-76CH00016, Brookhaven National Laboratory. 


\section{REFERENCES}

1. S.B. Desu and I.K. Yoo. Electrochemical Models of Failure in Oxide Perovskites. in $4^{\text {th }}$ International Symposium on Integrated Ferroelectrics. (1992).

2. G.E. Pike, W.L. Warren, D. Dimos, B.A. Tuttle, R. Ramesh, J. Lee, V.G. Keramidas, and J.T. Evans, Appl. Phys. Lett., in the press, (1995).

3. D.M. Smyth, Prog. Solid St. Chem., 15, 145-71, (1984).

4. R.B. Atkin and R.M. Fulrath, J. Amer. Ceram. Soc., 54(5), 265-70, (1971).

5. D.M. Smyth, Ferroelectrics, 116, 117-124, (1991).

6. D. Hennings and K.H. Haerdtl, Phys. Status Solidi A, 3(2), 465-74, (1970).

7. P.J. Schultz and K.G. Lynn, Reviews of Modern Physics, 60(3), 701-779, (1988). 